DOI 10.37882/2223-2982.2021.03-2.29

\title{
ЛЕКСИКО-СЕМАНТИЧЕСКИЕ ОСОБЕННОСТИ УПОТРЕБЛЕНИЯ АНГЛОАМЕРИКАНИЗМОВ В МОЛОДЕЖНОЙ ИНТЕРНЕТ-ПЕРЕПИСКЕ
}

\section{LEXICAL SEMANTIC FEATURES \\ OF THE ANGLO-AMERICANISMS USAGE IN YOUTH INTERNET CORRESPONDENCE \\ E. Nikitina \\ V. Vonog \\ A. Alekseeva \\ O. Filonchik}

Summary: The Anglo-Americanisms are often used in youth internet correspondence nowdays due their popularity among young people. It is noted that the borrowed lexical units do not correspond to their prototypes in the source language. When included in the lexical and semantic system of the Russian language, foreign words undergo semantic changes. When the lexical unit was introduced into the Russian language, it underwent increasing or decreasing in the volume of semantic meaning. In the future, borrowings, like all other native lexical units, show a tendency to develop a semantic structure.

Keywords: Anglo-Americanisms, internet correspondence, semantic changes, lexical units, borrowings, volume of semantic meaning, expressive synonyms.
B настоящее время процессы цифровизации, затронувшие все сферы социально-экономической деятельности, оказывают влияние и на взаимодействие молодежи в интернете, которое в большей степени происходит в режиме реального времени. Сочетание технологического и научного подходов формирует потребность в определении ключевых черт коммуникации современного поколения [Aida V. Kiryakova, Aleksandr N. Tretiakov, Vadim V. Kolga, Olga F. Piralova, and Bika B. Dzhamalova, 2016]. Часто такое общение реализуется в форме текстовых сообщений, лексика которых имеет ряд особенностей. В частности, в молодежной интернет-переписке часто используются англоамериканизмы - единицы, заимствованные из английского языка и из его американского варианта. Так наиболее часто встречаются такие слова как бро, хейт, лайк, забанить, го, абилка, ачивка, скрафтить, респект. В чатах также встречаются неформальные сокращения и на английском языке: $y w$ (You're welcome) -сокращение от фразы “всегда пожалуйста" или "обращайся"; np (No problem). Наиболее частое
Никитина Елена Александровна

К.филол.н., дочент, Сибирский федеральный университет (2. Красноярск)

injaz@inbox.ru

Воног Вита Витальевна

К.культурологии, дочент, Сибирский федеральный университет (2. Красноярск)

vonog_vita@mail.ru

Алексеева Анна Борисовна

Старший преподаватель, Сибирский федеральный университет (2. Красноярск)

annblok@mail.ru

Филончик Ольга Александровна

К.культурологии, дочент, Сибирский федеральный университет (2. Красноярск)

oly-fill@yandex.ru

Аннотация: Основной причиной использования англоамериканизмов в молодежной интернет-переписке является популярность английского языка у молодежи. Отмечается факт несоответствия заимствованных лексических единиц их прототипам в английском языке. При проникновении в русский язык англоамериканизмы претерпевают семантические изменения. В дальнейшем заимствования развиваются по законам заимствующего языка и получают новое семантическое значение.

Ключевые слова: англоамериканизмы, интернет-переписка, семантические изменения, лексические единицы, заимствования, объем семантического значения, экспрессивные синонимы.

сокращение, которое встречается - это ИМХО от англ. In My Humble Opinion (По моему скромному мнению).

Процесс заимствования играет большую роль в пополнении словарного состава языка. Под заимствованиями мы понимаем «все слова, взятые какого-либо языка» то есть любое «иноязычное слово» [5]. Причинами использования англоамериканизмов в молодежной интернет-переписке, на наш взгляд, является популярность английского языка у молодежи. Иностранные слова имеют перед исконными единицами то преимущество, что аттестуют говорящего в социальном плане более высоко. Особенно это касается англоамериканизмов. Большинство используемых англоамериканизмов являются экспрессивными синонимами, служащими для обозначения самых разнообразных эмоционально-экспрессивных оттенков значений. Англоамериканизму отдается предпочтение как обладающему большими экспрессивными и стилистическими возможностями слову в сравнении с единицами русского языка, например, айс 
(круто, отпад), трушный (крутой, настоящий).

Так же, на наш взгляд, англоамериканизмы придают шутливый характер переписке в интернете, например: сорян (прости, извини), РОФЛ (от англ. „катаюсь на полу от смеха" - ROFL) и т. д.

Другой причиной использования англоамериканизмов является тот факт, что заимствованные единицы способны более емко и просто выразить пространственные описательные обороты и тяжеловесные конструкции. Например, употребление единицы фейспалм (от англ. facepalm -рука лицо) имеет значение у молодежи «физический жест, при котором закрывается лицо, обозначая стыд или разочарование». В целях экономии языковых усилий употребляется и слово дедлайн (крайний срок выполнения какой-либо работы).

Следует отметить, что большую часть некоторые из этих выражений молодежь использует и в устной речи. Помимо этого, многие слова начинают употреблять и люди старшего возраста, например, сегодня активно используются лексические единицы, которые первоначально употреблялись в интернете молодежью, например: фолловер (последователь известного человека в сети интернета), хейтер (так называют тех, кто ощущает ненависть к чему-то или кому-то и делится своей неприязнью в интернете.), хайп (ажиотаж, шумиха).

В процессе заимствования необходимо отметить факт несоответствия заимствованных лексических единиц их прототипам в языке источнике. При употреблении иноязычного слова в молодежной интернетпереписке эти различия определяются следующими основными моментами: функционально-стилистической принадлежностью, объёмом семантической структуры и предметно-логической соотнесённостью [3]. Как свидетельствует анализ, в словарь молодежного сленга из английского языка проникают как стилистически нейтральные лексические единицы, так и заимствования с пометой разговорности. К данной группе относятся прежде всего заимствования-неологизмы: кринж - в значении «стыдно, неловко»; трэш (треш) - в значении «дрянь, хлам»; краш - в значении «внезапная влюбленность, привязанность к кому-либо».

В момент включения в лексико-семантическую систему русского языка иноязычные слова подвергаются семантическим изменениям. Прежде всего, обращает на себя внимание тот факт, что большинство многозначных слов заимствовались русским языком не во всех, а в одном, реже двух и более значениях. К. Готлиб указывает на то, что «иноязычное слово переходит в систему заимствующего языка только с некоторой частью своей смысловой структуры, причём половина исследуемых лексических единиц только с одним смысловым вари- антом. Количественное изменение объёма смысловой структуры в обоих языках характеризуется одним и тем же типом-ростом объёма смысловой структуры» [2]. В подавляющем большинстве из всех имеющихся значений заимствуется одно, реже два значения. Избирательность заимствуемого значения продиктована системным характером процесса заимствования. Как правило, заимствуются те значения, которые отсутствуют в комплексе значений соответствующего исконного слова. В дальнейшем заимствования, как и все другие исконные лексические единицы, обнаруживают тенденцию к развитию смысловой структуры.

Так, например, англоамериканизм треш (как вариант трэш) в английском языке имеет следующие значения:1. Вещь низкого качества, брак. 2 Отбросы, хлам; мусор [7]. При проникновении в русский язык лексическая единица претерпела увеличение объема семантического значения и используется в молодежном жаргоне сленге в следующих значениях:

- для передачи сильных эмоций - состояния восторга, выброса адреналина, негативна, возмущения и т.п.;

- для подчеркивания происходящего беспредела;

- описания чего-то через чур отрицательного, негативного;

- осуждение позорных, унизительных действий, повергающих в возмущение;

- характеристики своего плохого настроения;

- в качестве высмеивания чего-то пошлого, вульгарного, безумного, из ряда вон выходящего [7].

В ряде случаев из семантической структуры заимствованного слова в русский язык проникает лишь значение, снабжённое пометой разговорности. Слово флексить на молодежном сленге значит «хвастаться, выпендриваться». В английском языке глагол flex имеет следующие значения: 1. Сгибать, гнуть что-либо. 2. Сленг: показывать, что ты счастлив или гордишься чем-либо таким способом, что это может обидеть других [11].

В молодежный сленг проникает значение с пометой «сленг».

Процесс сокращения семантической структуры многозначного слова в момент его заимствования русским языком зачастую сопровождается изменением предметно-логической соотнесённости данной лексической единицы, что происходит на основе метафорических и метонимических переносов. Слово ісе имеет в английском языке значения: 1. лед. 2. амер. сленг: бриллиант, алмаз. Именно на основе значения, отмеченного пометой «амер. сленг.», происходит метафорический перенос и слово выступает в молодежной среде в качестве оценочного со значение «здорово, круто». 
Таким образом, анализ практического материала показал, что в молодежный жаргон, а в частности, интернет-переписку, проникают как стилистически нейтральные единицы, так и единицы с пометами slang, informal (разг.). В большинстве случаев заимствуются экспрессивные, оценочные слова. Такая лексика всегда имеет свойство обновляться, и заменяться новы- ми единицами.

Большинство заимствованных лексических единиц при проникновении в заимствующий язык обнаруживает сокращение семантического объёма. В дальнейшем заимствования развиваются по законам заимствующего языка и получают новое семантическое значение.

\section{ЛИТЕРАТУРА}

1. Голденков, М.A. ОСТОРОЖНО! HOT DOG! Современный активный English. - M.: ЧеР0, 2001. - 272c.

2. Готлиб К. Междуязычные аналогизмы французского происхождения в немецком и русском языках: Автореф. дис. ... канд. филол. наук. - Новосибирск, 1966. $-18 \mathrm{c}$.

3. Коротких Ю.Г. Лексические заимствования в современном немецком языке (на материале разговорной речи). - Воронеж, 1980. - 68с.

4. Крысин Л.П. Иноязычные слова в современном русском языке. - М.: Наука, 1968. - 208с.

5. Крысин Л.П. Иноязычные слова в современной жизни // Русский язык конца XX столетия //- М., 1996. - 480с.

6. Крысин Л.П. Словарь иностранных слов. - М., 1998. - 500с.

7. Словарь молодежного слэнга - [Электронный ресурс] Режим доступа: https://znachenieslova.ru/slovar/youthslang/tresh

8. Х Хауген Э. Процесс заимствования. - В кн.: Новое в лингвистике: Языковые контакты. М.1972, вып. 6, С. 344-383.

9. Чернышева И.И. Лексические заимствования в лексико-семантической системе языка: (на материале немецкого языка). - В кн.: Лингвистика и методика в высшей школе. М., 1970, вып.5, С. 68-73.

10. Aida V. Kiryakova, Aleksandr N. Tretiakov, Vadim V. Kolga, Olga F. Piralova, and Bika B. Dzhamalova. Experimental Study of the Effectiveness of College Students' Vocational Training in Conditions of Social Partnership - International Electronic Journal Of Mathematics Education, Volume 11, Issue 3 (2016), pp. $457-466$.

11. Cambridge dictionary - [Электронный ресурс] Режим доступа: https://dictionary.cambridge.org/dictionary/english/flex

○ Никитина Елена Александровна (injaz@inbox.ru), Воног Вита Витальевна (vonog_vita@mail.ru), Алексеева Анна Борисовна (annblok@mail.ru), Филончик Ольга Александровна (oly-fill@yandex.ru).

Журнал «Современная наука: актуальные проблемы теории и практики»

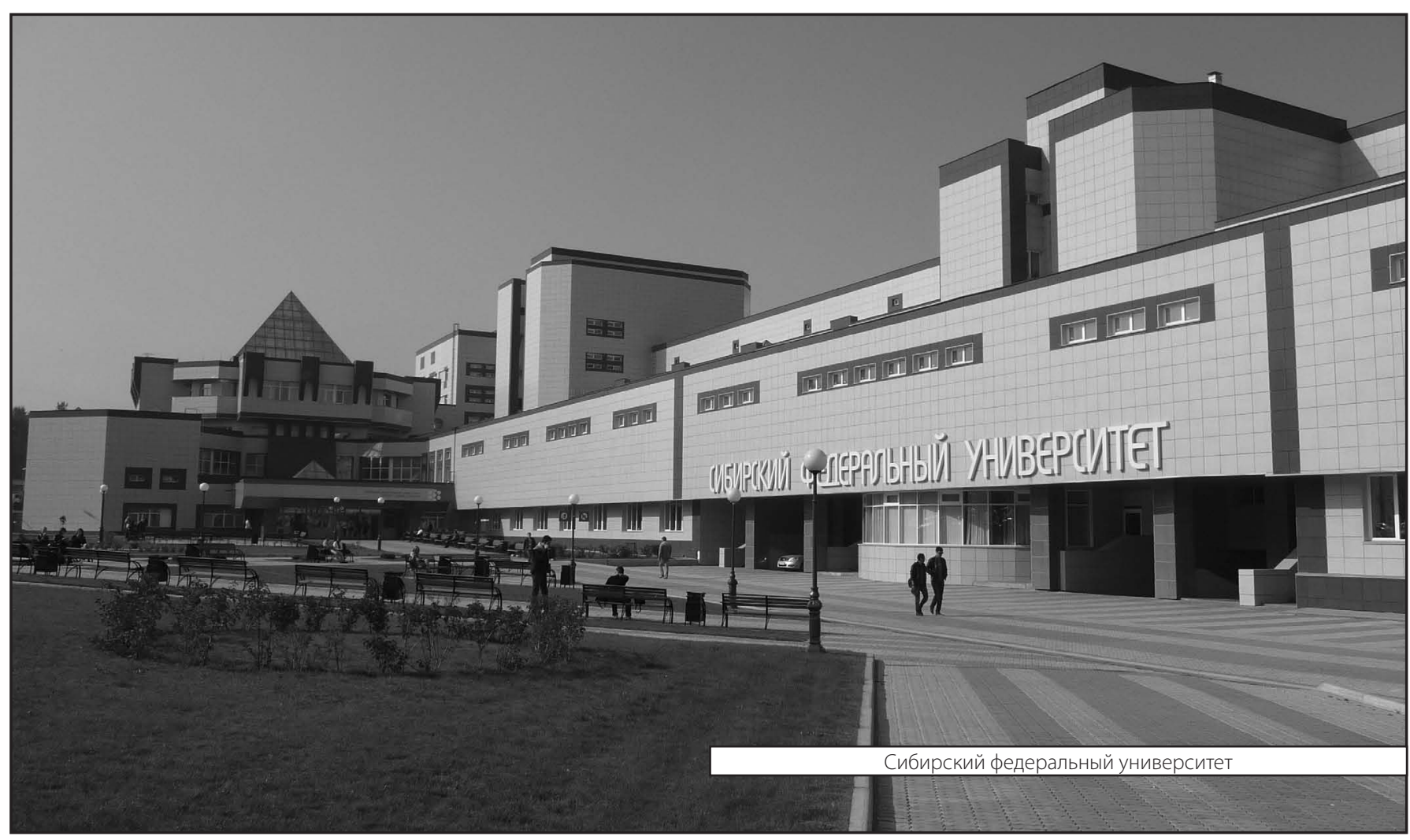

